R. Maingi, M. Bell, R. Bell, T. Biewer, C. Bush, C.S. Chang, D. Gates, S. Kaye, H. Kugel, B. LeBlanc, R. Maqueda, J. Menard, D. Mueller, R. Raman, S. Sabbagh, V. Soukhanovskii, and the NSTX Team

October 2003

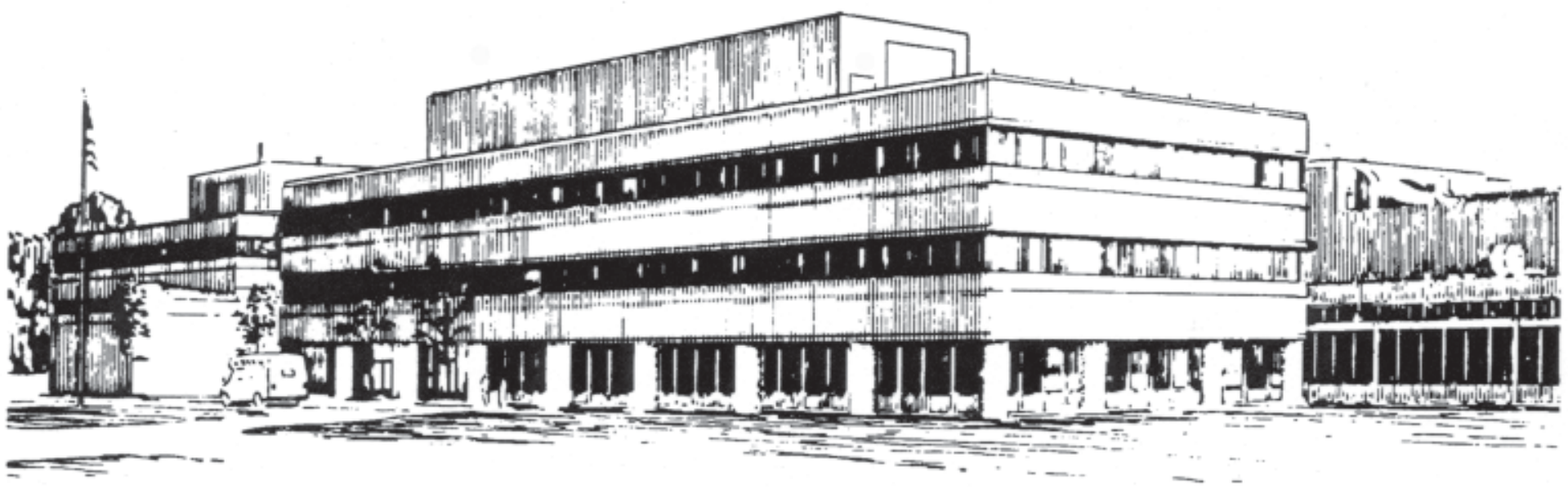




\section{PPPL Reports Disclaimer}

This report was prepared as an account of work sponsored by an agency of the United States Government. Neither the United States Government nor any agency thereof, nor any of their employees, makes any warranty, express or implied, or assumes any legal liability or responsibility for the accuracy, completeness, or usefulness of any information, apparatus, product, or process disclosed, or represents that its use would not infringe privately owned rights. Reference herein to any specific commercial product, process, or service by trade name, trademark, manufacturer, or otherwise, does not necessarily constitute or imply its endorsement, recommendation, or favoring by the United States Government or any agency thereof. The views and opinions of authors expressed herein do not necessarily state or reflect those of the United States Government or any agency thereof.

\section{Availability}

This report is posted on the U.S. Department of Energy's Princeton Plasma Physics Laboratory Publications and Reports web site in Fiscal Year 2004. The home page for PPPL Reports and Publications is: http://www.pppl.gov/pub_report/

DOE and DOE Contractors can obtain copies of this report from:

U.S. Department of Energy

Office of Scientific and Technical Information

DOE Technical Information Services (DTIS)

P.O. Box 62

Oak Ridge, TN 37831

Telephone: (865) 576-8401

Fax: (865) 576-5728

Email: reports@adonis.osti.gov

This report is available to the general public from:

National Technical Information Service

U.S. Department of Commerce

5285 Port Royal Road

Springfield, VA 22161

Telephone: $1-800-553-6847$ or

(703) $605-6000$

Fax: (703) 321-8547

Internet: http://www.ntis.gov/ordering.htm 


\title{
Effect of Gas Fueling Location on H-mode Access in NSTX
}

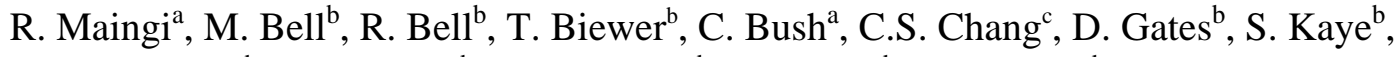

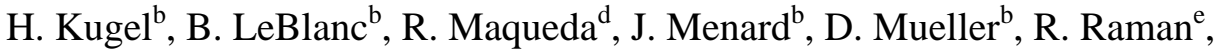 \\ S. Sabbagh ${ }^{\mathrm{f}}$, V. Soukhanovskii ${ }^{\mathrm{b}}$, and the NSTX Team \\ ${ }^{a}$ Oak Ridge National Laboratory, PO Box 2009, Oak Ridge TN, 37831, USA \\ ${ }^{b}$ Princeton Plasma Physics Laboratory, PO Box 451, Princeton, NJ 08543, USA* \\ ${ }^{c}$ New York University, New York NY, USA \\ ${ }^{d}$ Los Alamos National Laboratory Los Alamos, NM, USA \\ ${ }^{e}$ University of Washington, Seattle, WA \\ ${ }^{f}$ Columbia University, New York, NY USA \\ * correspondence address \\ first author email: rmaingi@pppl.gov \\ Submitted 07-Oct-2003
}

\begin{abstract}
The dependence of H-mode access on the poloidal location of the gas injection source has been investigated in NSTX. We find that gas fueling from the center stack midplane area produces the most reproducible H-mode access with generally the lowest L-H threshold power in lower single-null configuration. The edge toroidal rotation velocity is largest (in direction of the plasma current) just before the $L-H$ transition with center stack midplane fueling, and then reverses direction after the $L-H$ transition. Simulation of these results with a 2-D guiding center Monte Carlo neoclassical transport code is qualitatively consistent with the trends in the measured velocities. Double-null discharges exhibit H-mode access with gas fueling from either the center stack midplane or center stack top locations, indicating a reduced sensitivity of $H$ mode access on fueling location in that shape.
\end{abstract}

PACs: $52.55 \mathrm{Fa}$

It has been previously reported that in both MAST[1] and NSTX[2], fueling from the center stack region (i.e. high-field side, HFS) allowed more reproducible H-mode access than fueling from the outer midplane or other low-field side (LFS) locations. Quantifying this behavior in NSTX has been challenging, however. Prior to HFS fueling, it was difficult to obtain routine H-modes with LFS fueling in NSTX. In contrast, long reproducible $\mathrm{H}$-modes were obtained during the first attempt with HFS fueling following the first high temperature $\left(\sim 350{ }^{\circ} \mathrm{C}\right)$ bake-out of the graphite plasma facing surfaces. We 
note that HFS gas fueling widened[3] the H-mode access space and reduced the power threshold somewhat in COMPASS-D, as compared with LFS fueling. In addition, HFS fueling was about twice as efficient as LFS fueling during DIII-D ELMy H-modes[4], although the gross fueling efficiencies were less than $1 \%$ in both cases.

The present H-mode access scenario in NSTX uses LFS fueling for the gas pre-fill before $t=0$ and during the current ramp up prior to neutral beam initiation, which typically starts at $\mathrm{t} \sim 0.1 \mathrm{sec}$. The LFS injection is usually terminated just before NBI turn-on, when HFS fueling is initiated. Due to the long tube used for HFS midplane injection, the efolding decay time of the flow rate[5] is $\sim 0.55 \mathrm{sec}$, resulting in limited control of the fueling rate.

Motivated by these and other experimental results, a neoclassical transport theory was developed[6,7] to examine the dependence of the momentum balance on the poloidal location of the gas injection source. The theory suggests that the charge-exchange viscous drag is higher for neutral sources on the LFS than the HFS, because the ions lost to charge exchange have the highest toroidal velocity $\left(\mathrm{v}_{\varphi}\right)$ at the weakest toroidal field $\left(\mathrm{B}_{\varphi}\right)$ point, i.e. the outer midplane. As a result, both the $v_{\varphi}$ and radial electric field $\left(E_{r}\right)$ have terms with $1 / \mathbf{R}_{*}{ }^{2}$, where $\mathbf{R}_{*}$ is the major radius at which gas fuels the plasma. This effect should be most apparent in a spherical torus because it features the largest variations in $\mathbf{R}_{*}$ from the inner to outer midplane.

Additional gas injectors at various poloidal locations were commissioned in NSTX to test this prediction and improve gas fueling control. Fig. 1 shows the four injector locations: HFS midplane(black), HFS top in upper corner (orange), outer midplane (blue), and lower X-point region (white). These injectors were used to fuel routine lowersingle-null, upper-single null, and double-null discharges with plasma current $\mathrm{I}_{\mathrm{P}} \sim 0.9$ MA, toroidal field $\mathrm{B}_{\mathrm{t}} \sim 0.45 \mathrm{~T}$, and 3.2 $\mathrm{MW}$ of neutral beam injected (NBI) power. The unfiltered light patterns from these discharges showed localized emission near the gas injector locations (see Fig. 2). Most of this visible light originates from $D_{\alpha}$ recycling light, suggesting that the neutral density poloidal variation is affected by the choice of puff location. We do not quantify this variation in this paper, but merely use it as an indicator the neutral density poloidal distribution can be modified to qualitatively test the neoclassical theory prediction above. 
The first three injectors were each used to fuel a lower-single null discharge during the neutral beam injection (NBI) phase, e.g. starting at $\mathrm{t}=0.08 \mathrm{sec}$ in Fig. 3. Prior to NBI (the pre-fill and during plasma current ramp-up), all of the gas fueling was injected with a separate outboard injector. The total gas input during NBI was well matched in the three cases, and the time dependence of the gas injection rate was reasonably well matched. However the HFS midplane injector discharge (black trace) exhibited H-mode access at $\mathrm{t}=0.26 \mathrm{sec}$, whereas the other two discharges with LFS and HFS top fueling exhibited prolonged L-modes and early reconnection events. This experiment was conducted near the beginning of the 2003 run period, when the L-H transition power was between one and two NBI sources, i.e. higher than normal threshold levels. We previously reported [2] that the LFS injector only produced H-mode access at an NBI power between 1.6 and 3.2 MW (between 1 and 2 sources) in conditions[8] where the L-H threshold power was measured at $\sim 650 \mathrm{~kW}$ with HFS midplane fueling, i.e. below 1 full NBI source. In that set of experiments, the required NBI power for H-mode access became similar between the two fueling locations as the gas rate was reduced, but the reproducibility was still better with the HFS midplane injector. The lower limit on fueling rate was set by the occurrence of locked modes with either injector. At very high fueling rates, the H-mode could not be accessed at all with LFS gas puffing, even though access was maintained with the HFS midplane injector. These observations imply that the neutral density magnitude itself likely affects H-mode access criteria. Finally we note that fueling with a combination of the X-point injector and LFS injector failed to produce H-mode transitions, and the temporal characteristics of those discharges were quite different from the other injectors discussed above. Additional experiments are required to fully characterize these differences.

Fig. 4 compares the magnitude of the edge toroidal rotation for two HFS midplane discharges with a LFS fueled discharge and an X-point + LFS fueled discharge. We note that the edge rotation speed for the HFS midplane discharges is marginally but consistently higher (co- $\mathrm{I}_{\mathrm{p}}$, reproducible in other discharges from this experiment) than for the other fueling locations just before the time of the L-H transition of the HFS midplane fueled discharges. Note that the LFS and X-point + LFS fueling cases failed to access $\mathrm{H}$ mode and resulted in shorter discharges (see Fig. 3). The edge rotation velocity is obtained from Abel-inversions of passive edge rotation signals of C-III light [9]. The diagnostic has $\mathrm{a} \sim 3 \mathrm{~cm}$ edge spatial resolution and integrates over $10 \mathrm{msec}$. The rotation 
velocity at the radius of peak emission $\left(\mathrm{R} \sim 1.48 \mathrm{~m}\right.$, normalized poloidal flux $\psi_{\mathrm{N}} \sim 0.97$ 0.98 ) is plotted, because it has the lowest statistical and inversion errors. We note that the poloidal rotation array was unavailable during this experiment, precluding a statement on the effect of fueling location on $\mathrm{E}_{\mathrm{r}}$ in this paper.

In double-null discharges, the differences between fueling from the HFS midplane and HFS top were more subtle. Discharges fueled by either injector allowed H-mode access at comparable power levels; the major difference was the location of the $\mathrm{D}_{\alpha}$ fueling light, which was centered about the midplane for midplane fueling and near the upper corner for top fueling (fig. 2).

We have simulated the effect of neutral source poloidal location variation in the lower-single null configuration with a new 2-D Monte Carlo, guiding center code (XGC)[10] with neoclassical and/or anomalous cross-field transport in an X-point geometry. The poloidal distribution of the neutral fueling source is a Gaussian plus a baseline as a function of the poloidal angle, $\theta$. The location of the peak of the Gaussian is selected to match the fueling location. The ratio of the maximum fueling source of the Gaussian to the baseline value is set (somewhat arbitrarily at a high value for exploration) to 50. The integral of the fueling source term (in effect, the maximum of the Gaussian) is constrained by the input edge density value. The model edge temperature is constrained by the input experiment value, and the anomalous cross-field coefficients are selected to approximately match the $\mathrm{n}_{\mathrm{e}}$ and $\mathrm{T}_{\mathrm{e}}$ profiles. Three simulations were conducted: one of the LFS midplane fueled L-mode phase, one of the HFS midplane fueled L-mode phase, and one of the HFS midplane fueled H-mode phase after the L-H transition. An anomalous cross-field diffusion coefficient of $2 \mathrm{~m}^{2} / \mathrm{s}$ was used to model the L-mode phases, which was then reduced to $0.1 \mathrm{~m}^{2} / \mathrm{s}$ for modeling of the $\mathrm{H}$-mode phase.

Fig. 5 shows that the flux surface averaged toroidal rotation is predicted to be higher for the HFS midplane fueling than the LFS fueling cases, consistent with the analytic theory [6]. The toroidal rotation is in the co-NBI direction, except close to the separatrix where rotation is negative due to the negative $\mathrm{E}_{\mathrm{r}}$. Fig. 6 shows that the edge toroidal rotation is predicted to be reduced in the H-mode phase, and the width of the counter rotation region is increased. This occurs because of the larger negative $E_{r}$ in the H-mode phase and the larger edge pressure gradient, both of which drive counter rotation. We note that the predictions show in Figs. 5 and 6 are qualitatively consistent with the data in 
Fig. 3-4, albeit with the acknowledgement that the diagnostic does not presently have the spatial resolution to measure the fine structure of the predicted velocity for $\psi_{\mathrm{N}}$ between 0.99 and 1.0. Note that the simulation does not attempt to explore the dynamics of the transition itself, but rather the pre- and post-transition states.

In summary, we have conducted experiments to test the effect of gas injector location on H-mode access and quality. We find that HFS midplane fueling leads to the most reproducible access in lower-single null discharges with an obviously lower L-H threshold power. These results are qualitatively consistent with an analytic theory and Monte Carlo transport calculations. In double-null configuration, H-mode access is equally well achieved by HFS midplane or HFS top corner injection, which may be due to improved trapping of gas along the inboard boundary in double-nulls.

The degree to which the poloidal dependence of the fueling source can be affected by the gas puff location, however, requires extensive neutral density measurements. At a minimum the neutral density distributions need to be measured at the inner and outer midplanes, as well as the X-point regions. Such measurements would allow an assessment of the importance of local and main chamber recycling/fueling, as compared with divertor fueling in the vicinity of the $\mathrm{X}$-point regions.

\section{Acknowledgements}

This research was supported by US D.O.E. contracts DE-AC05-00OR22725, DEAC02-76CH03073, W-7405-ENG-36, and grants DE-FG02-99ER54524, DE-FG0299ER54519 and DE-FG02-99ER54523. We gratefully acknowledge the contribution of the NSTX technical staff and neutral beam operations staff. 


\section{Figure captions}

1 - gas injector locations in NSTX.

2 - visible light emission (unfiltered) during fueling from different poloidal locations. Circles highlight the regions of enhanced emission.

3 - comparison of discharges fueled from the HFS midplane (black-solid), the outboard side (blue-dashed), and HFS top (orange-dash-dot). All discharges had the same NBI timing. The gas flow rate time dependence $(b)$ is slightly different for the HFS top injector, but the total gas input (c) is well matched. The toroidal rotation (d) at the edge near the separatrix is marginally higher (more co-I ${ }_{p}$ ) just prior to the L-H transition in the HFS midplane fueling discharge, but then turns sharply negative after the L-H transition at $t \sim 0.255 \mathrm{sec}$. The HFS top and LFS fueling discharges did not undergo an L-H transition, as shown in the $D_{\alpha}(e)$.

4 - comparison of edge toroidal rotation for discharges fueled from the HFS midplane (black-solid and green-dash-dot-dot), the outboard side (blue-dashed), and HFS top (orange-dash-dot). The edge rotation was marginally higher for the two HFS midplane discharges which exhibited H-mode transitions (times indicated by the vertical bars).

5 - comparison of predicted toroidal rotation with HFS midplane (inside) and LFS (outside) fueling with the XGC code.

6 - comparison of predicted toroidal rotation in H-mode and L-mode phases of HFS midplane fueling with the XGC code. 


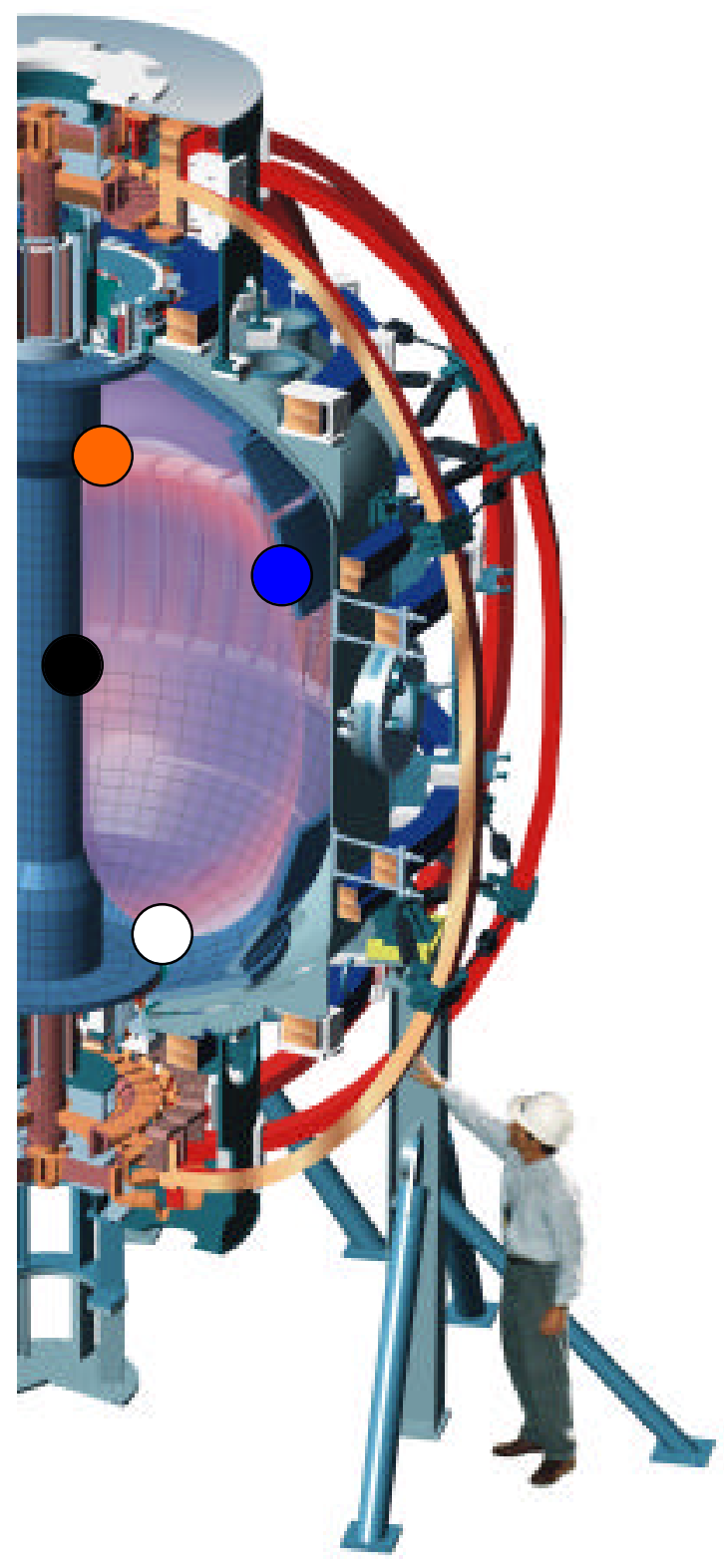

Fig. 1 

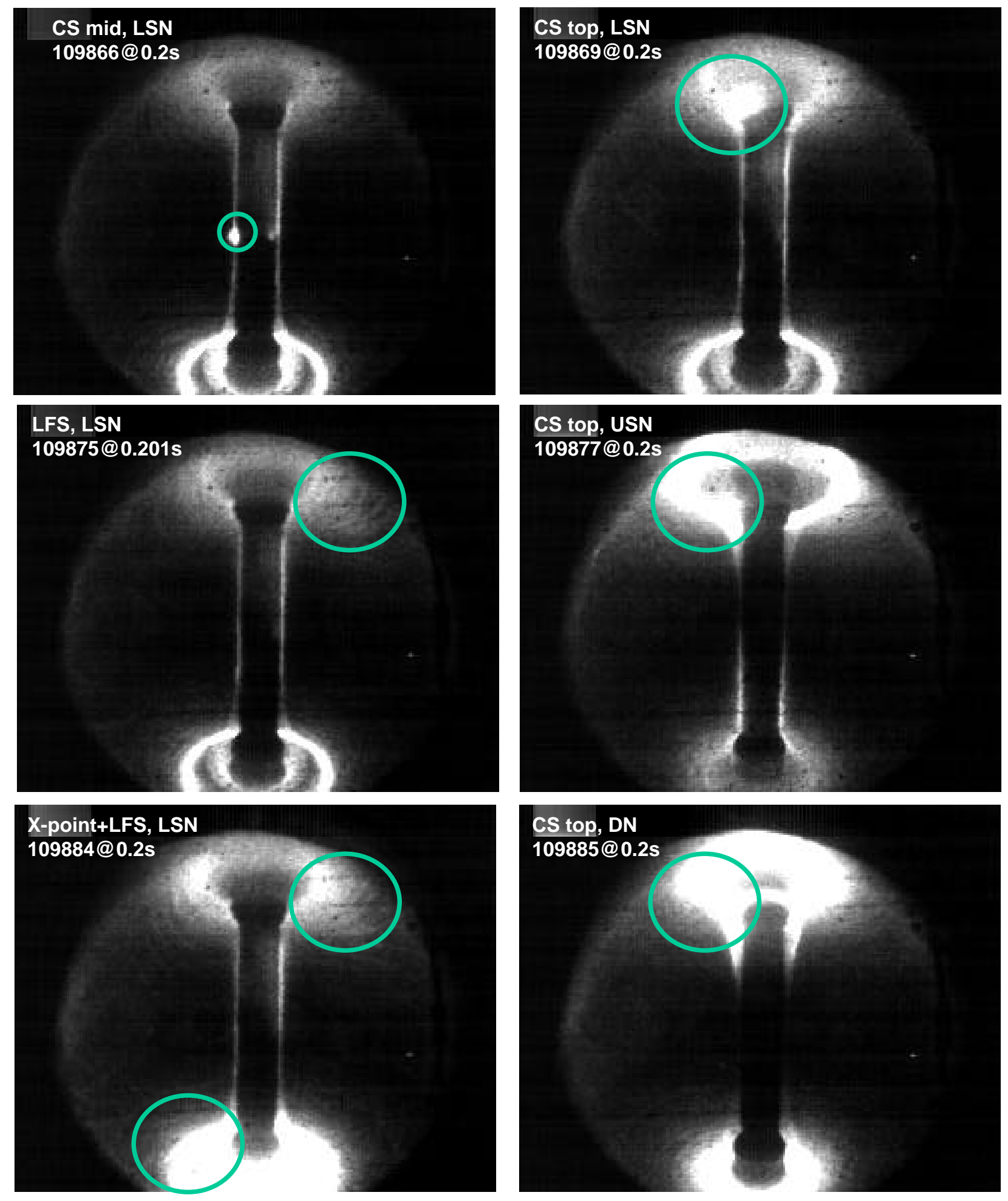

Fig. 2. 


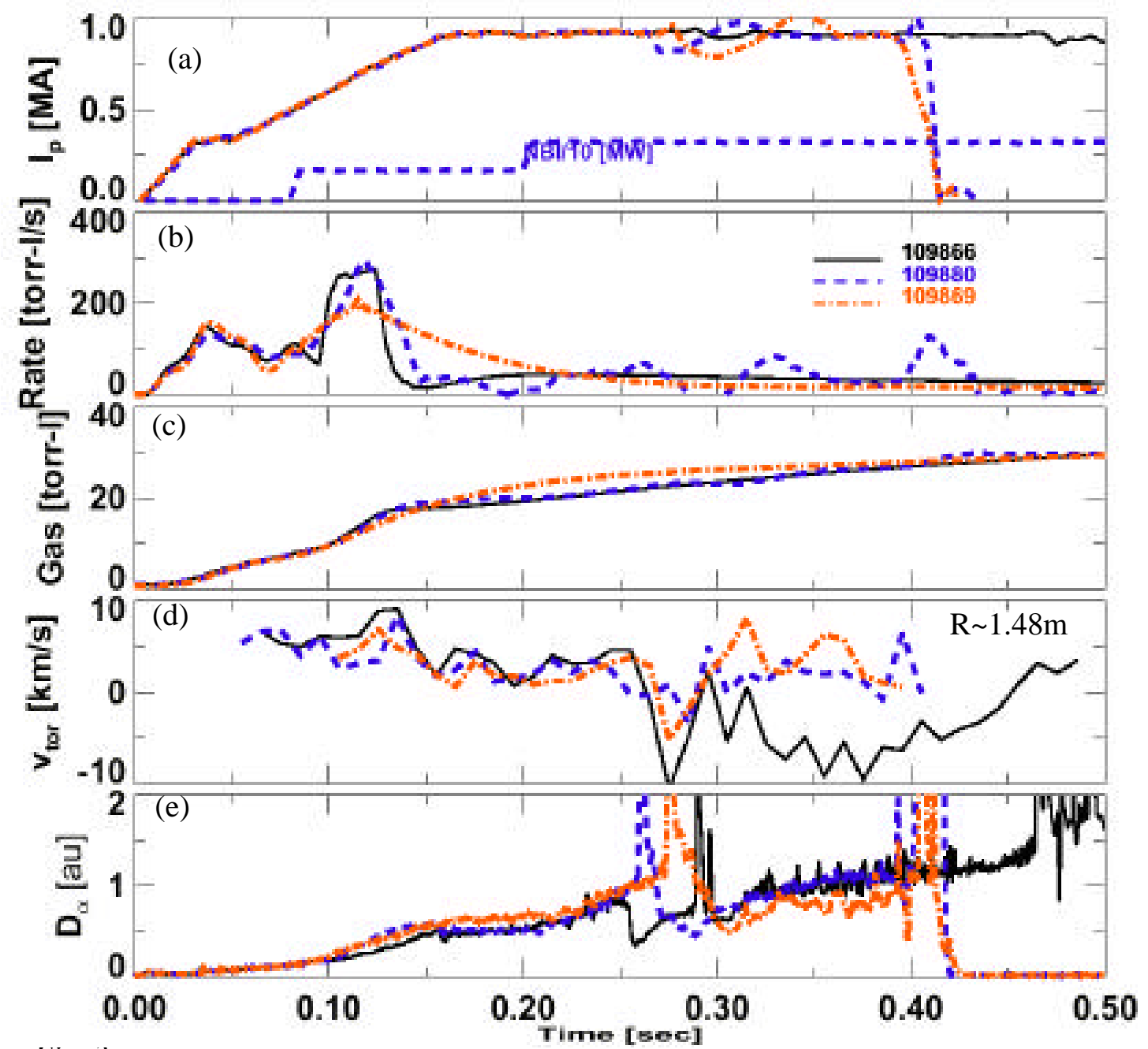

Fig. 3 


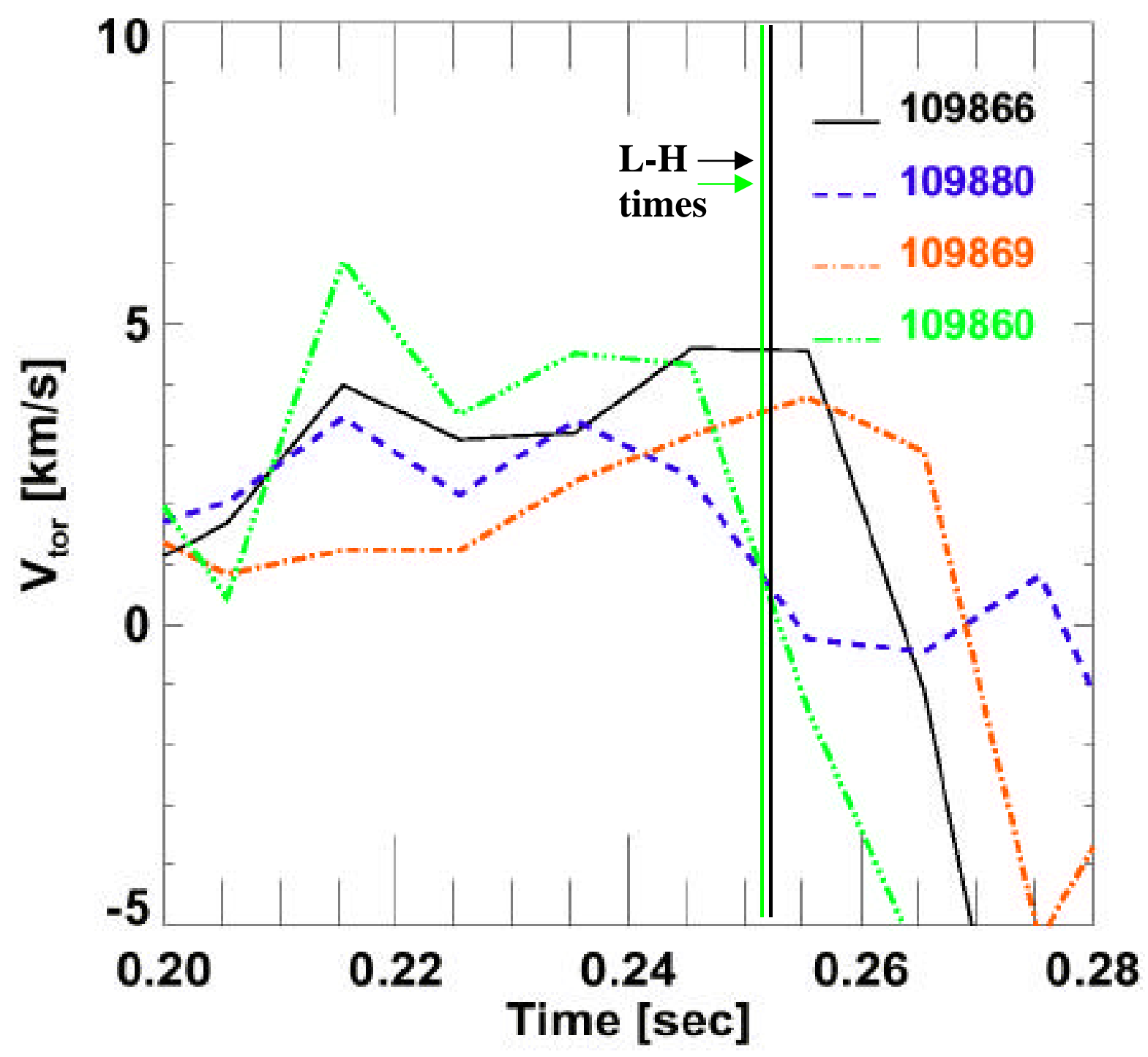

Fig. 4 


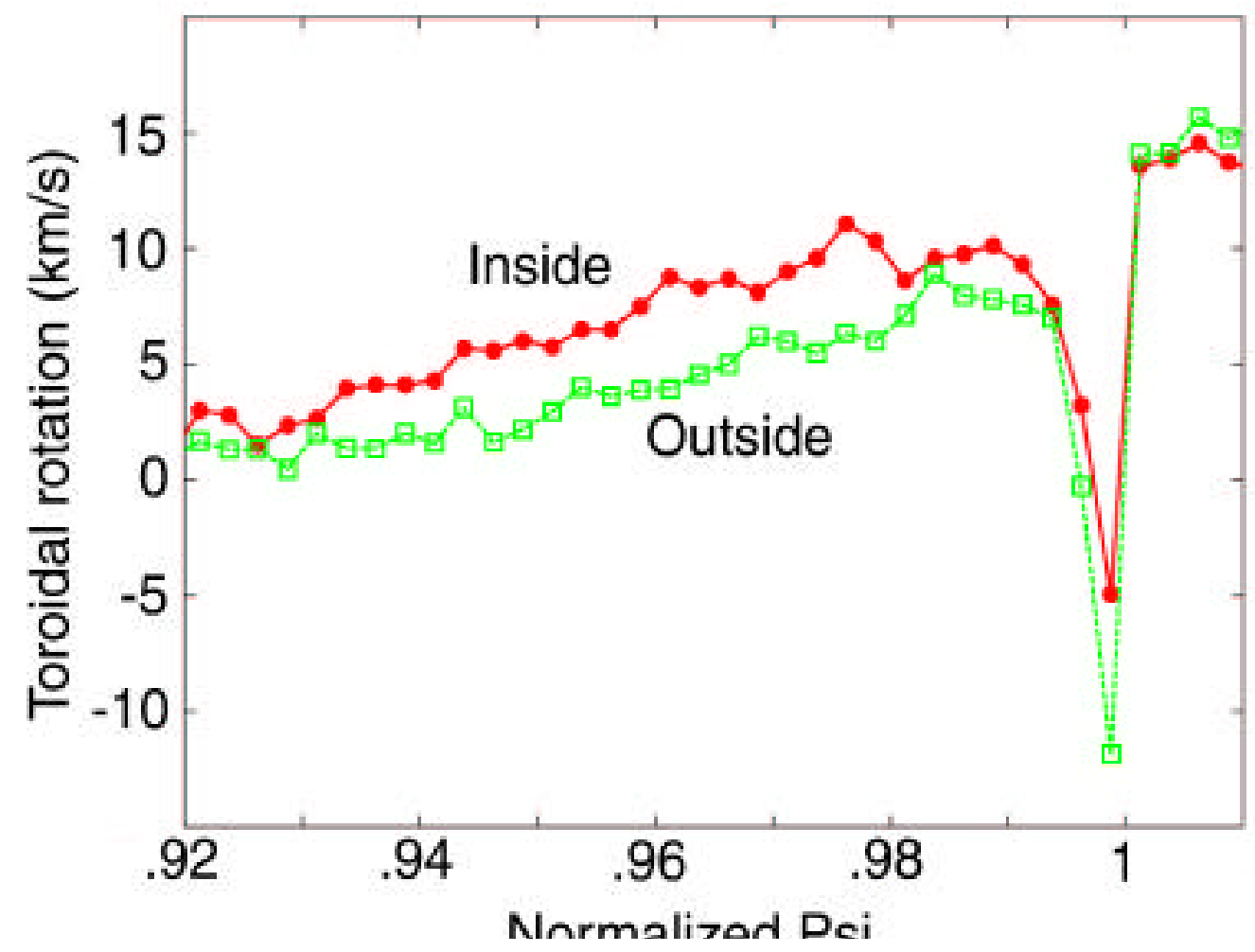

Fig. 5 


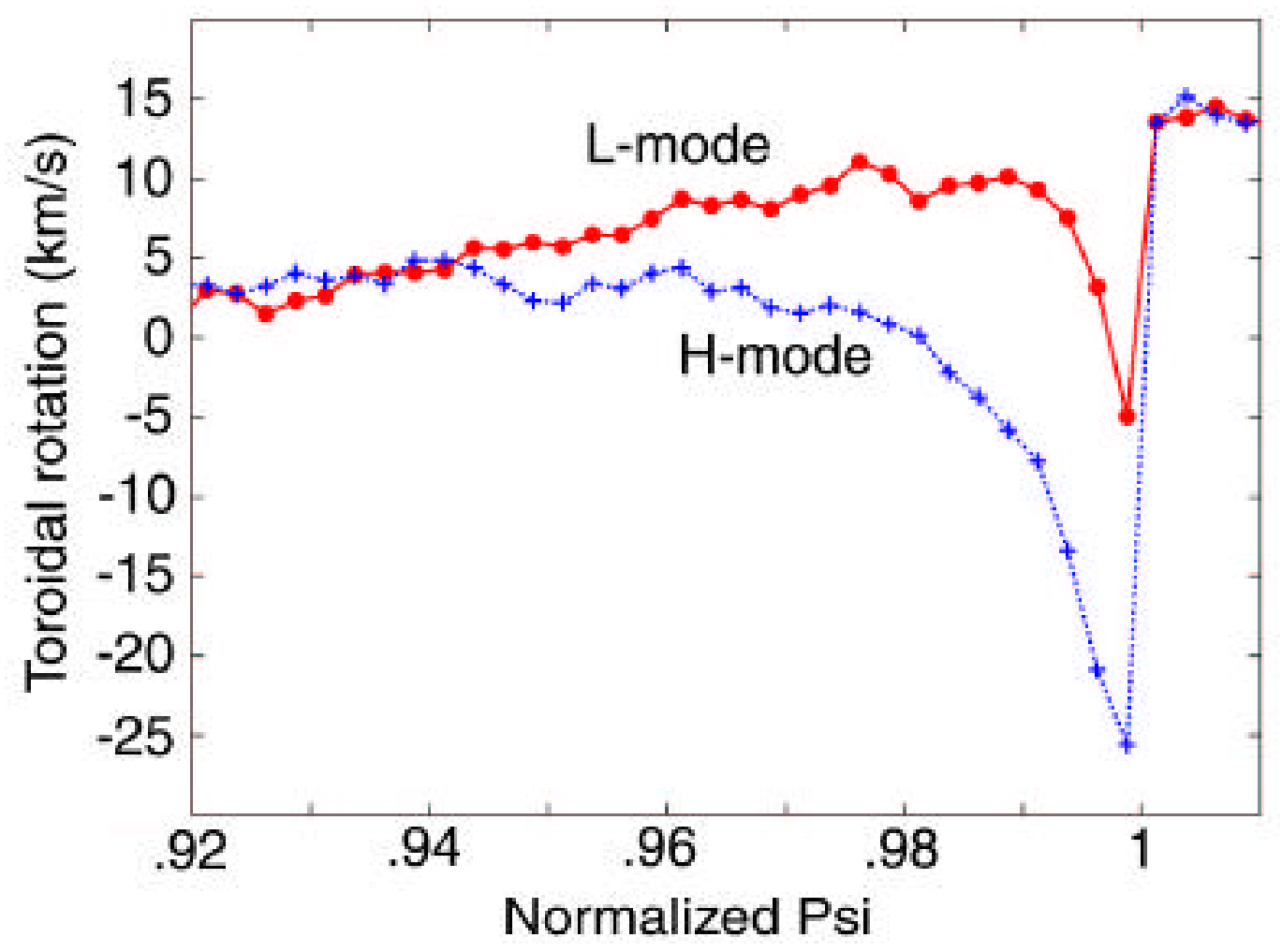

Fig. 6 


\section{References}

[1] A.R. Field, et. al., Plasma Phys. Contr. Fusion 44 (2002) A113.

[2] R. Maingi, et. al., Nucl. Fusion 43 (2003) 969.

[3] M. Valovic, et. al., Plasma Phys. Contr. Fusion 44 (2002) A175.

[4] L.R. Baylor, et. al., J. Nucl. Mater. 313-6 (2003) 530.

[5] H.W. Kugel, et. al., "NSTX High-Field Side Gas Fueling System", Proc. of the 2003 SOFE conference on Fusion Technology, San Diego, CA, 14-17 Oct. 2003.

[6] T. Fulop, P. Helander, and P.J. Catto, Phys. Rev. Letts. 89 (25 Nov. 2002) \#225003;

[7] P. Helander, T. Fulop, and P.J. Catto, "Controlling Edge Plasma Rotation Through Poloidally Localized Fueling”, submitted to Phys. Plasma, 05/2003.

[8] C.E. Bush, et. al., Plasma Phys. Contr. Fusion 44 (2002) A323.

[9] T. Biewer, et. al., "An Edge Rotation and Temperature Diagnostic on NSTX", submitted to Rev. Sci. Instr., 8/03.

[10] C.S. Chang, S.h. Ku, and H. Weitzner, "Monte Carlo Particle Simulation of Edge Pedestal and Er-Layer Formation Including Neutral Particle and Anomalous Diffusion Effects," submitted to Phys. Plasma, 10/03. 


\section{External Distribution}

Plasma Research Laboratory, Australian National University, Australia

Professor I.R. Jones, Flinders University, Australia

Professor João Canalle, Instituto de Fisica DEQ/IF - UERJ, Brazil

Mr. Gerson O. Ludwig, Instituto Nacional de Pesquisas, Brazil

Dr. P.H. Sakanaka, Instituto Fisica, Brazil

The Librarian, Culham Laboratory, England

Mrs. S.A. Hutchinson, JET Library, England

Professor M.N. Bussac, Ecole Polytechnique, France

Librarian, Max-Planck-Institut für Plasmaphysik, Germany

Jolan Moldvai, Reports Library, Hungarian Academy of Sciences, Central Research Institute for Physics, Hungary

Dr. P. Kaw, Institute for Plasma Research, India

Ms. P.J. Pathak, Librarian, Institute for Plasma Research, India

Ms. Clelia De Palo, Associazione EURATOM-ENEA, Italy

Dr. G. Grosso, Instituto di Fisica del Plasma, Italy

Librarian, Naka Fusion Research Establishment, JAERI, Japan

Library, Laboratory for Complex Energy Processes, Institute for Advanced Study, Kyoto University, Japan

Research Information Center, National Institute for Fusion Science, Japan

Dr. O. Mitarai, Kyushu Tokai University, Japan

Dr. Jiangang Li, Institute of Plasma Physics, Chinese Academy of Sciences, People's Republic of China

Professor Yuping Huo, School of Physical Science and Technology, People's Republic of China

Library, Academia Sinica, Institute of Plasma Physics, People's Republic of China

Librarian, Institute of Physics, Chinese Academy of Sciences, People's Republic of China

Dr. S. Mirnov, TRINITI, Troitsk, Russian Federation, Russia

Dr. V.S. Strelkov, Kurchatov Institute, Russian Federation, Russia

Professor Peter Lukac, Katedra Fyziky Plazmy MFF UK, Mlynska dolina F-2, Komenskeho Univerzita, SK-842 15 Bratislava, Slovakia

Dr. G.S. Lee, Korea Basic Science Institute, South Korea

Institute for Plasma Research, University of Maryland, USA

Librarian, Fusion Energy Division, Oak Ridge National Laboratory, USA

Librarian, Institute of Fusion Studies, University of Texas, USA

Librarian, Magnetic Fusion Program, Lawrence Livermore National Laboratory, USA

Library, General Atomics, USA

Plasma Physics Group, Fusion Energy Research Program, University of California at San Diego, USA

Plasma Physics Library, Columbia University, USA

Alkesh Punjabi, Center for Fusion Research and Training, Hampton University, USA

Dr. W.M. Stacey, Fusion Research Center, Georgia Institute of Technology, USA

Dr. John Willis, U.S. Department of Energy, Office of Fusion Energy Sciences, USA

Mr. Paul H. Wright, Indianapolis, Indiana, USA 
The Princeton Plasma Physics Laboratory is operated by Princeton University under contract with the U.S. Department of Energy.

\author{
Information Services \\ Princeton Plasma Physics Laboratory \\ P.O. Box 451 \\ Princeton, NJ 08543
}

Phone: 609-243-2750

Fax: 609-243-2751

e-mail: pppl_info@pppl.gov

Internet Address: http://www.pppl.gov 